\title{
Support system for management of shares ergonomic
}

\author{
Raphael Pacheco da Rocha ${ }^{\mathrm{a}}$, Mario Cesar Rodriguez Vidal ${ }^{\mathrm{a}}$ \\ ${ }^{a}$ Department of Production Engineering, COPPE / UFRJ, City University, Block G, G207, Rio de Janeiro, Brazil
}

\begin{abstract}
This article discusses the development of a computerized support to demands for treatment of a wide spectrum and diverse nature. Developed under SPM platform (Situação, Problema e Melhoria), the practitioner seeks to provide an ergonomic aid from the identification and characterization of the processes of analysis demands. The interest of a technological support the practice of ergonomics is a domestic origin, which already features a wide universe. For purposes of this article will be drawn the line defined by the universe in the Federal Public Service occupations within the guidelines set Subsystem Integrated System for Health Care Workers of the Federal Government. The development of this system initially intended to assist the practitioner in ergonomics mapping situations in which the federal public servant has been undergoing for the second time that can classify and then treat them.
\end{abstract}

Keywords: ergonomics, management, ergonomics tools, technology, methodology

\section{Introduction}

This article discusses the development of a computerized support to assist the practitioner in ergonomics survey and mapping characterization of demands on ergonomics.

Developed in the light of the experiences of the Group of Ergonomics and New Technologies (COPPE / UFRJ) the practice of ergonomics, most notably within the segment of the ergonomic assessment, is addressing a well-defined group of users, the professional practitioners of ergonomics. It takes ambition to expand this world today limited to professionals with high expertise.

The development of a tool to aid with the purpose of popularization of practices socially important has also been dubbed in the area of ergonomics and digital inclusion.

Under this privilege, the automation of a process of intervention is proposed as a technique to facilitate the digital inclusion of ergonomics in the world.

Currently, techniques and production methods are being employed in businesses and private industries in order to optimize production costs. However, the quest for a lean production is resulting in an increase of ergonomic factors that impact both in productive activity, and health workers involved in production.
The Federal Government through the area of Social Security, presented the data on accidents at work in the private sector in the triennium 2006-2008. In relation to accidents from the federal public sector, which occurs when there is information missing, decentralized. The government paid attention to the fact, creating in 2009 the Subsistema Integrado de Atenção à Saúde do Trabalhador (SIASS), and in this sector, poor supervision and full of ergonomic factors to be addressed that this development has to meet.

Table 1

Accidents at work

\begin{tabular}{|l|c|c|c|}
\hline \multicolumn{1}{|c|}{ Cause } & 2006 & 2007 & 2008 \\
\hline Accidents at work & 407426 & 417036 & 438536 \\
\hline Accidents at course & 74636 & 79005 & 88156 \\
\hline
\end{tabular}

\section{Methodology}

To meet this demand would require the use of a methodology for characterization of all work situations in the world of federal public sector. Ergonomic Analysis and its variants, in spite of adversity situations, have a canonical scheme that articulates different forms of action. It is always important to emphasize that the Ergonomic Analysis is a specific option to elucidate the second level, deeper and more fo- 
cused than the first level assessments, and that can be addressed in other ways.

Note that for the application of the canonical form of Ergonomic Analysis of Work - AET, it is the combination of an ergonomic analysis perspectives combined observational and conversational references to the application of verification and contextualized by an analysis.

In applying the canonical form of the AET, we highlight two important moments in its methodological framework: the first is from the establishment of demand management to the demand(s) ergonomic(s), a point essential to its continuity, which from this point is starts the second time, after which the focus can establish a pre-diagnostic hypotheses from the problems, those who will later be used to compose the working models of the problem. It is the first step that appears a possibility of targeting. Some organizations gather a great quantity and diversity of issues that do not know how to identify, much less how to treat them.

To fulfill this research we chose to systematically Ergonomic Assessment by allowing a mapping of ergonomic factors and direct demands that require deepening, ie the development of further studies.

The ergonomic assessment methods - also called functional analysis [1] differs orthogonally ergonomic analysis of work, since they are in forms of coverage and inclusion of a vast repertoire of plausible treatment notes, which have become widely used by designers, especially in the architectural field.

About this prerogative, the use of conversational and observational techniques as applied to private sector organizations, it was thought in the development of a help system that meets the practitioner ergonomics of the federal public service, description of work situations, providing an overview of situational ergonomic factors maintained by your plants.

\section{Information System Situações, Problemas e Melhorias (SISPM)}

The development was the basis of a systematic appraisal methodology.

MATTOS [2] made a comparison between the methods practiced in ergonomic analysis. The choice of this method as a basis for development was based on a comprehensive mapping address situations of non-conformities and their hardships, and considering an essential starting point, notably a lack of available benchmarks of good practice.
The practice of this method, using the system is the development of six stages: the first is the mapping of activities to be enjoyed. This step will be featured work situations that will be targeted by the appraisal process, where the practitioner Ergonomics must register even if the course of incipient actions taken in the situation that is being appreciated, in the second stage, the practitioner will identify and describe the problems raised for consideration, where the record of the impacts (problems) will be held in a descriptive and could be grounded as a photograph. The third step consists of seeking regulatory frameworks that sustain them in the form of law issues raised in the review process. Usually at this point it is contemplated Norm at least 17, [3] but not limited to use of others standards. The fourth step consists in finding the root cause of the problem, once that, had been identified and characterized the practitioner should seek the aspect Ergonomics causal impact he said. The fifth step is the description of the opportunity to improve the situation for problem raised. If there is no one solution applies the practitioner should score this as a study situation further, because his background and understanding require more time to be a possible suggestion. The sixth and last step is the description of the justification opportunity for improvement points in the fifth step.

The Information System for Ergonomic Assessment was based on the structure of the SPM method of assessment developed by the GENTE/COPPE. Being developed on the platform of the Internet, using the programming language Personal Hypertext Preprocessor - PHP, where your choice was based on flexibility, popularity, and the amplitude characteristic of a non-proprietary language, and free.

The system will provide an overview of the organization conformities found, maintained and practiced in its facilities, in addition to ergonomic factors that need to be worked out.

This approach determines the formation of an ergonomic framework that enables companies, climb parameters of maturity in their Ergonomics processes [4]. Treatments micro ergonomics, oriented toward the preparation of notes from the regulatory frameworks and opportunities for improvement.

Currently there are applications that can be applied to the analysis process, but notes that its application is restricted to a well-defined context. 


\section{Conclusion}

Work situations in the context of the federal public service does not currently follow the progress of the actions of supervisory inspectors of the Ministry of Labor and Employment. In some supervisory actions in the private sector, auditors do not act as agents only punitive, but provide a framework for organizing issues that need to be worked directing if any, some, as the object of further study [5]. Those who use technology to support not only the solution but also as a competitive advantage when developing new technology.

This research included the computerization of the method Ergonomic Assessment SPM, where the result after application is the organization can provide an overview of the problems in the workplace.

The application of computerized support did not contemplate the elimination of all aspects of nonconformities maintained by work situations, but will serve as an initial step, where by mapping and provide subsidies for the contextualization of these situations in the workplace kept the Brazilian public service.

Some studies of interface already started to take place. Below is a presentation of ideas for the main interface of the system.

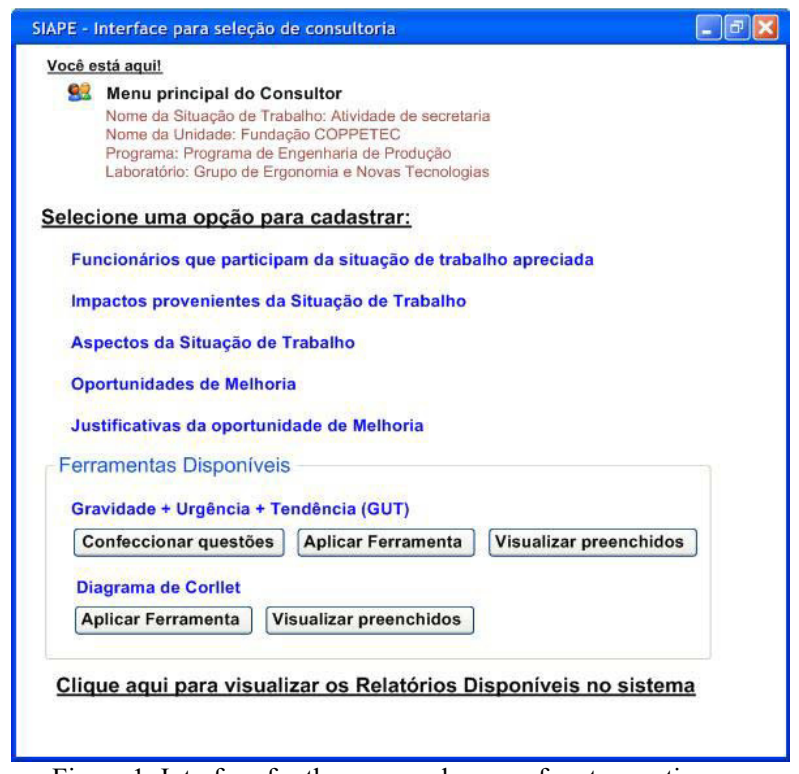

Figure 1: Interface for the proposed menu of system options

\section{References}

[1] Pikaar R.N. (2006) New Challenges: Ergonomics in Engineering Projects In: Pikaar R.N., Koningsveld E.F.P. and Settels P.J.M. Meeting Diversity in Ergonomics Elsevier Ltda. Amesterdam, pp. 29-64

[2] Mattos C. M. M., 2009, Confrontação entre os métodos de ação ergonômica: análise ergonômica do trabalho e apreciação ergonômica SPM. M.Sc., COPPE/UFRJ, RJ, Rio de Janeiro, Brasil.

[3] NR 17, Norma Regulamentadora em Ergonomia (117.000-7). (www.mte.org.br/legislacao) acesso em 18 de agosto de 2011

[4] Vidal, M.C.R. et. alii , 2009, "The ergonomic maturity of a company enhancing the effectiveness of ergonomic process." Anais do XVII World Congress on Ergonomics, Beijing.

[5] Martins, J. M., 2011, A Ação ergonômica aplicada à inspeção do Trabalho: Proposta de estratégia de intervenção para melhoria dos locais de trabalho. D.Sc., UFRJ/Centro de Tecnologia, Rio de Janeiro, RJ, Brasil. 